\title{
Ionization enhancements in sporadic E- layers prior to some major Indian earthquakes
}

\author{
O.P. Singh and Birbal Singh ${ }^{1}$ \\ Department of Physics, Faculty of Engineering \& Technology, RBS College, Bichpuri, \\ Agra- 283 105, India \\ 1) Department of Electronics \& Communication Engineering, Faculty of Engineering \& \\ Technology, RBS College, Bichpuri, Agra- 283 105, India
}

\begin{abstract}
Ionospheric data obtained from Ahmedabad are analysed to examine the role of three major Indian earthquakes that occurred at Bihar- Nepal border on 20 August 1988, Latur on 30 September 1993, and Jabalpur on 22 May 1997 on E-layer perturbation. The percent enhancements in the nighttime critical frequency $\left(\mathrm{f}_{0} \mathrm{E}_{\mathrm{s}}\right)$ over the monthly median are calculated and their variations are examined from 20 days before to 3 to 4 days after the occurrence of the earthquakes. The results show that the $f_{0} E_{s}$ are enhanced $3-20$ days before the occurrence of the earthquakes during both the pre and post-midnight hours. The effects of magnetic storms are identified but they are not found to vitiate the above results. Various mechanisms, which may be responsible for $f_{0} E_{\mathrm{s}}$ enhancements, are discussed and the role of intensified electric fields over epicentral zones is emphasized.
\end{abstract}

Key words: Ionospheric perturbation, Sporadic E-layer, Earthquake

\section{Introduction}

The ionospheric perturbations related to earthquakes were identified almost four decades ago when Alaskan earthquake occurred on $28 \mathrm{March}, 1964$ (Davies and Baker, 1965). Since then many workers have reported such perturbations on the basis of satellite and ground based observations. For example, Datchenko et al. (1972) and Reutov and Morenko (1995) have reported abnormal night airglow emissions before the occurrence of the earthquakes and explained their occurrence in terms of increasing plasma density anomalies at $F_{2}$ layer or processes in the E-layer. An increase in critical frequency of F-layer $\left(\mathrm{f}_{0} \mathrm{~F}_{2}\right)$ was observed by Fatkulin et al. (1989) two days before the occurrence of earthquake. Pulinets et al. $(1991,1994)$ have reported reduction in morning time $\mathrm{f}_{0} \mathrm{~F}_{2}, 2-7$ days before the occurrence of earthquakes and this effect was observed over a large area covering $30^{\circ}$ latitude and $60^{\circ}$ longitude. Liu et al. $(2000,2001)$ and Chuo et al. (2002) have discussed the $f_{0} F_{2}$ variations related to Taiwan earthquakes and found precursors ( afternoon reductions ) 1-6 days prior to the main shocks. Perturbations in the ionospheric E-layers, characterized by an increase in critical frequencies $\left(f_{0} E_{s}\right)$, has been observed by many workers prior to the occurrence of nearby earthquakes (Gokhberg et al.,1988; Liperovski et al., 1992; Pulinets et al.,1994; Ondoh, 2000; Ogawa et al., 2002). It has been suggested that the variations in the ionospheric parameters such as enhancement or reduction in the $\mathrm{f}_{0} \mathrm{~F}_{2}$ and an enhancement in $\mathrm{f}_{0} \mathrm{E}_{\mathrm{s}}$ can be used for earthquake prediction purposes. Recent results in this field have been compiled in three excellent 
monographs (Hayakawa and Fujinawa, 1994; Hayakawa, 1999; Hayakawa and Molchanov, 2002).

In addition to the $\mathrm{E}$ and $\mathrm{F}$ layer perturbations as mentioned above it has also been found that there are localized reductions in the height of the lower boundary of the ionosphere due to the earthquakes. For example, Hayakawa et al.(1996a, b) have studied the phase and amplitude variations of fixed frequency omega VLF transmitter signals $(f=10.3 \mathrm{KHz}$ ) radiated from Tsushima and observed at Inbo ground station about $1000 \mathrm{Km}$ apart in Japan. They, in fact, introduced the concept of "termination times" which are defined as the times of sunrise and sunset when the phase (or amplitude) of the received signal exhibit a characteristic minima. They found that the termination times showed an anomalous time shifts 2-3 days before the occurrence of Hyogo-ken Nanbu earthquake (popularly known as Kobe earthquake) which occurred on 17 January 1995 with magnitude $M=7.2$.They interpreted this result in terms of the lowering of the ionosphere reflection height by about $0.7 \mathrm{Km}$ possibly caused by either radon emission or the concentration of gravity waves during the earthquake. The VLF data corresponding to Kobe earthquake was processed in greater detail using the termination time method by Molchanov et al. (1998) who have shown that the results of Hayakawa et al. (1996a, b) are statistically significant also and reflection height could be decreased by about $2 \mathrm{Km}$. Singh et al. (2004) have made a similar study using $19.8 \mathrm{KHz}$ NWC signals and have found night time amplitude decreases caused by moderate seismic activities along the propagation path which have been interpreted in a similar mechanism as suggested by Hayakwa et al. (1996a, b).

In one of our recent publications (Singh et al., 2004) we have reported the ionospheric effects of six major earthquakes that occurred in India during last 15 years between $1988-2001$ by analyzing the $\mathrm{f}_{0} \mathrm{~F}_{2}$ data and have shown that the $\mathrm{f}_{0} \mathrm{~F}_{2}$ are reduced both in the pre and postmidnight sectors prior to the occurrence of main shocks. In the pre-midnight sector the reduction is between $24-35 \%, 0-4$ days before the main shocks, and in the post- midnight sector it is between $18-30 \%, 1-15$ days before the main shocks.

In the present paper we analyse the nighttime ionospheric data to examine the effect of these earthquakes on sporadic E-layers $\left(\mathrm{f}_{0} \mathrm{E}_{\mathrm{s}}\right)$. The results show that the $\mathrm{f}_{0} \mathrm{E}_{\mathrm{s}}$ are enhanced in both the pre and post-midnight sectors prior to the occurrence of the earthquakes.

\section{Ionospheric, earthquake, and $K_{p}$ index and $D_{s t}$ data}

During the last 15 years six major earthquakes have occurred in India, which have caused considerable damage to life and property. These earthquakes are: Bihar-Nepal earthquake (20August, 1988), Uttarkashi earthquake (20 October, 1991), Latur earthquake (22 May, 1997), Chamoli earthquake (29 March, 1999), and Bhuj earthquake (26 January, 2001). In order to examine the effect of these earthquakes on the E-region ionosphere we have attempted to analyse the ionospheric data obtained from Physical Research Laboratory, Ahmedabad (latitude $23.01^{6} \mathrm{~N}$, longitude $72.36^{\circ} \mathrm{E}$ ), India. Unfortunately, the $\mathrm{f}_{0} \mathrm{E}_{\mathrm{s}}$ data are available corresponding to three earthquakes only, which are Bihar-Nepal earthquake, Latur earthquake, and Jabalpur earthquake. Hence, in the present paper we consider these three earthquakes only and analyse the relevant data. The locations of these earthquakes are shown in the map of Fig. 1 by abbreviated words 
BHR-NPL, LTR, and JBL respectively. Also shown is the location of ionospheric station Ahmedabad by AHD.

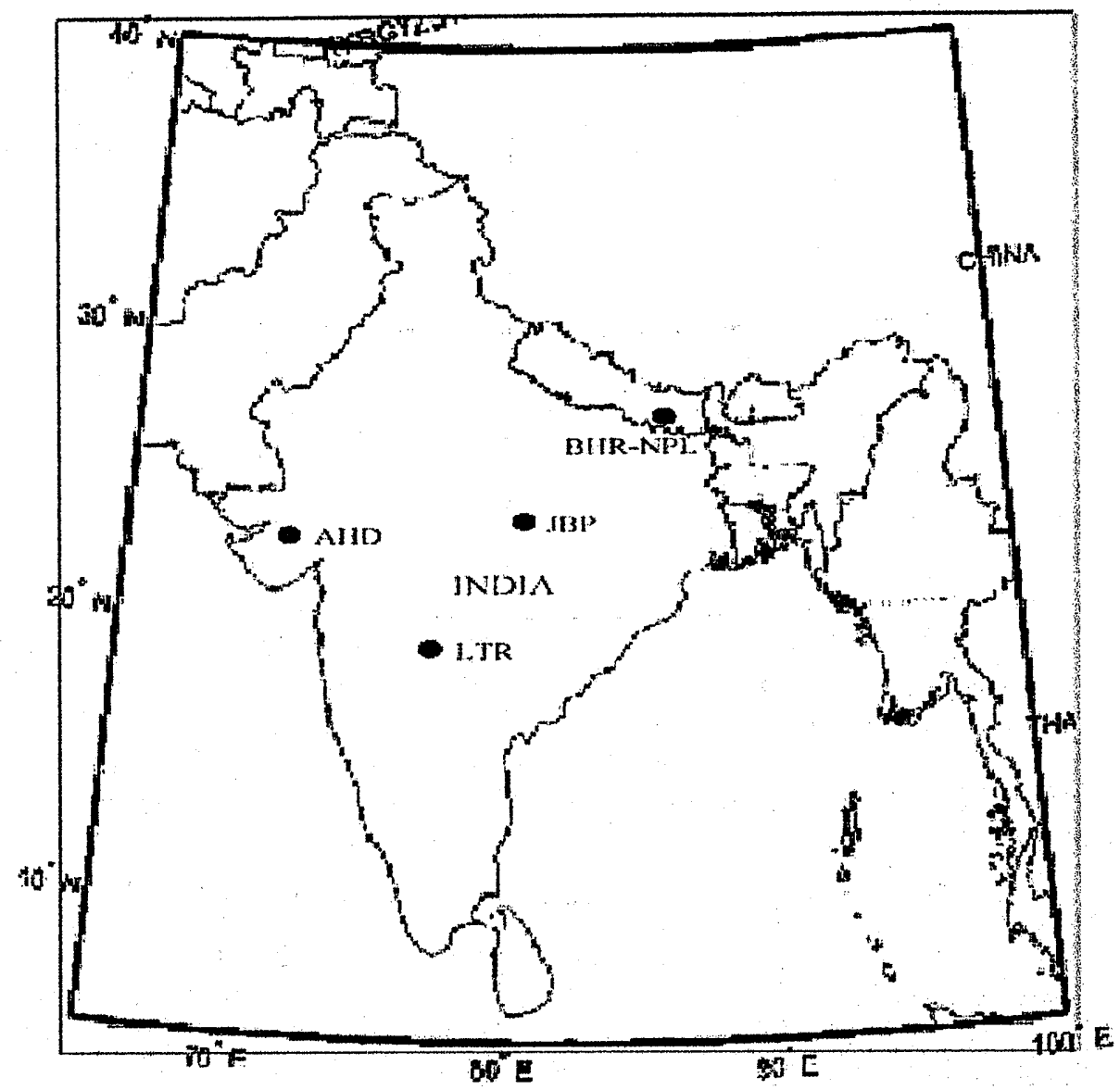

Fig. 1. Map of India showing the locations of three major earthquakes by solid circles. Also shown is the location of ionospheric station Ahmedabad ( AHD ).

Details of the earthquake data, obtained from India Meteorological Department, New Delhi, India, are given in Table 1.

It is well known that the ionosphere is disturbed during magnetic storms also in which large increase or decrease of the electron density and height is noticed (Appleton and Ingram, 1935; Berkner et al., 1939; Obayashi, 1954; Matsushita, 1959; Warren, 1969). Prolonged and severe magnetic storms are found to influence the low latitude ionosphere significantly than the isolated ones (Jain and Singh, 1977). Further, it should be mentioned here that ionospheric responses to magnetic storms are varied and highly dependent on the latitude, time of occurrence, 
and severity of the storms. In general a time delay of about 12 hours is involved in the ionospheric response to the storms. While ionospheric responses to geomagnetic storms are

Table 1. Details of the three earthquakes considered

\begin{tabular}{|l|l|l|l|l|l|l|l|}
\hline $\begin{array}{l}\text { Date of } \\
\text { occurrence }\end{array}$ & Location & $\begin{array}{l}\text { Time } \\
\text { (IST) }\end{array}$ & $\begin{array}{l}\text { Latitude } \\
\left({ }^{(} \mathbf{N}\right)\end{array}$ & $\begin{array}{l}\text { Longitude } \\
\left({ }^{\circ} \mathbf{E}\right)\end{array}$ & Magnitude & Depth & $\begin{array}{l}\text { Distance } \\
\text { from } \\
\text { AHD (km) }\end{array}$ \\
\hline 20.08 .1988 & $\begin{array}{l}\text { BHR-NPL } \\
\text { Border }\end{array}$ & $2309 \mathrm{hrs}$ & 26.72 & 86.63 & 6.6 & 35 & 2500 \\
\hline 30.09 .1993 & Latur & $0355 \mathrm{hrs}$ & 18.07 & 76.62 & 6.3 & 12 & 1100 \\
\hline 22.05 .1997 & Jabalpur & $0325 \mathrm{hrs}$ & 18.07 & 80.06 & 6.0 & 35 & 1600 \\
\hline
\end{tabular}

- $\quad \mathrm{IST}=\mathrm{UT}+5.50$ hours

of negative kind and large at high and mid-latitudes the responses are modest and of positive kind at low latitudes especially during daytime hours. During nighttime both of the positive and negative responses are possible at low and equatorial latitudes (Behnke, 1970; Wright, 1971; Lakshmi et al., 1983). We consider $K_{p}$ index and $D_{s t}$ index data to study the effect of magnetic storms, which are obtained from Indian Institute of Geomagnetism, Colaba, Mumbai, India and World Data Centre-C2, Kyoto University, Kyoto, Japan respectively.

\section{Results and discussion}

In the recent studies made by Ondoh and Hayakawa $(1999,2002)$ and Ondoh $(2003)$ to investigate the precursory effects of the earthquakes on the sporadic E-layers, it has been shown that there are enhancements in critical frequency of sporadic E-layer a few days before the occurrence of earthquakes. In these studies they have examined the variation of hourly values of $\mathrm{f}_{0} \mathrm{E}_{\mathrm{s}}$ with respect to the monthly median values. On a similar line we follow an analysis procedure in which we calculate the percent enhancements in hourly $\mathrm{f}_{0} \mathrm{E}_{\mathrm{s}}$ relative to monthly median values. We choose nighttime data $(1800 \mathrm{hr}-0600 \mathrm{hr})$ only and divide them into two groups, pre-midnight hours $(1800 \mathrm{hr}-0000 \mathrm{hr})$ and post-midnight hours $(0000 \mathrm{hr}-0600 \mathrm{hr}$ ). Since the data is not continuous and there are some intermittent gaps we take six days running mean of the peak values of the percent enhancements, both in the pre-midnight hours and postmidnight hours. The variations of $f_{0} E_{s}$ for 20 days before the occurrence of each earthquake are shown in the top panels of Figs. 2(a) - 2(c). In order to study the post earthquake effect the data length is extended by 2 to 3 days more. The days of occurrence of earthquakes along with their magnitudes are shown by inverted arrows in the top panels of each figure.

In order to examine the effect of magnetic storms on $\mathrm{f}_{0} \mathrm{E}_{\mathrm{s}}$ we show in the middle panel the variation of $K_{p}$ index. The $K_{p} \geq 6$ normally indicates severe magnetic storms which have 
pronounced influence on the variation of ionospheric parameters (Carpenter, 1967; Taylor, 1968; Chappel et al., 1970). We also analyse the data in the light of the Dst index variation during the days on which large enhancements in $\mathrm{f}_{0} \mathrm{E}_{\mathrm{s}}$ in the pre-midnight and post-midnight hours were observed prior to the occurrence of the three earthquakes considered. The variations of $D_{s t}$ index for these three cases are shown in the bottom panel of each figure. However, it may be noted here that the low latitude ionosphere is influenced by large reduction in $D_{s t}\left(D_{s t} \leq-100\right)$ only (B.M. Reddy, Personal communication, November, 2003). In the following we discuss the effect of the above-mentioned earthquakes case by case.

\section{Case - I : Bihar - Nepal earthquake of 20 August 1988}

The results of the study of Bihar - Nepal earthquake $(M=6.6)$, which occurred on 20 August 1988, are shown in Fig 2(a). The top panel of this figure shows the six days running mean of the peak values of percent enhancements for pre-midnight (solid circles) and postmidnight hours (solid squares).
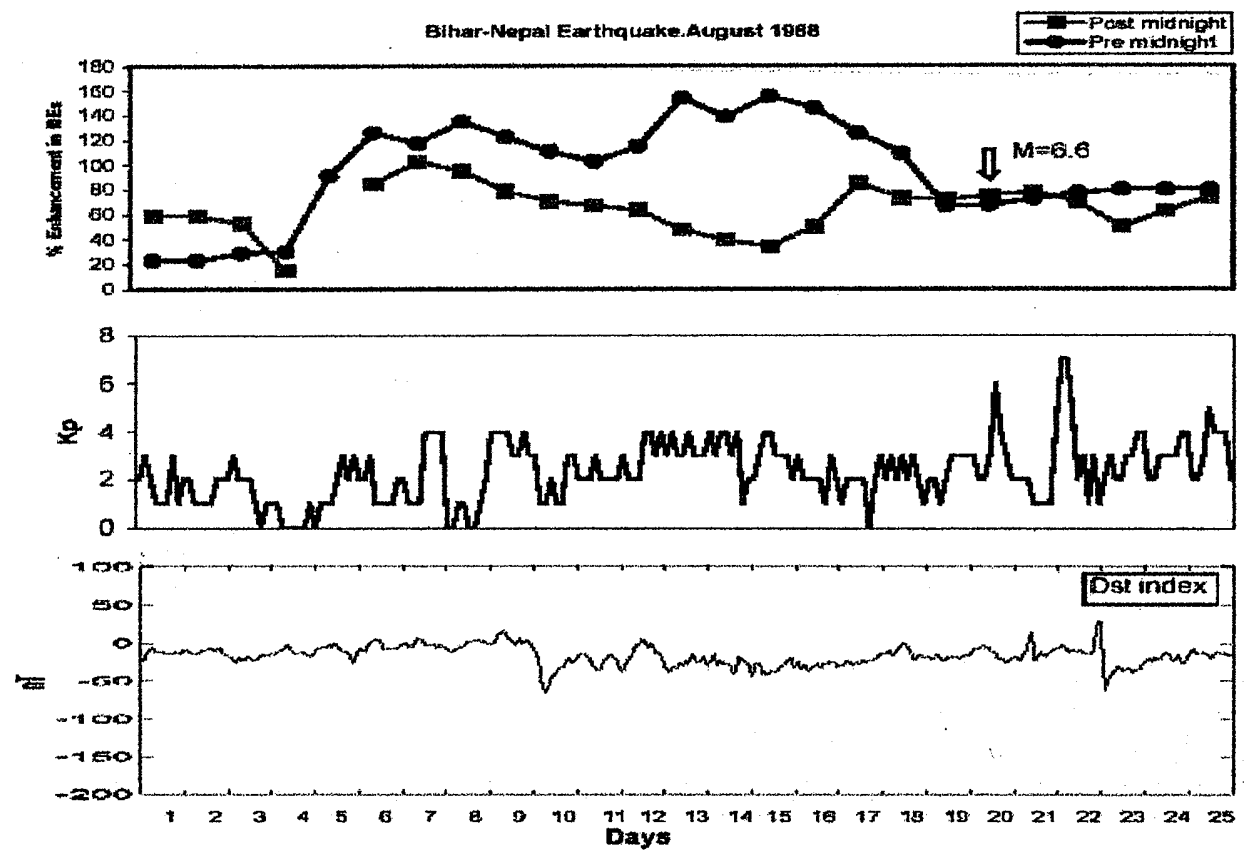

Fig. 2a. (Top) Percent enhancement during pre - midnight ( solid circles ) and postmidnight (solid squares) in $\mathrm{f}_{0} \mathrm{E}_{\mathrm{s}}$ from monthly median for 25 days in the month of August, 1998. The earthquake ( $M=6.6$, shown by downward arrow) occurred at Bihar - Nepal Border on 20 August, 1998. (Middle) $\mathrm{K}_{\mathrm{p}}$ index variation. (Bottom) $D_{\mathrm{st}}$ index variation on the days under consideration. 
The gap in post-midnight curve on 5 August is due to non-availability of data. In the middle and bottom panels we show the variations in magnetic indices $K_{p}$ and $D_{s t}$ respectively for the period of 1-25 August 1988. The pre-midnight data shows that the enhancements in $f_{0} E_{s}$ starts from 5 August, 15 days before the earthquake and the maximum enhancement of $155 \%$ is observed on 15 August, five days before the occurrence of the earthquake. In case of postmidnight hours the maximum enhancement of $102 \%$ is observed on 7 August which gradually reduces to $34 \%$ on 15 August and then increases to $85 \%$ on 17 August, 3 days before the occurrence of the earthquake. There is no abnormal variation in the data after the earthquake up to 25 August as seen in the figure except a minor reduction in post midnight data on 23 August. The variation of $K_{p}$ index, shown in middle panel, shows that the $K_{p}$ is small $\left(K_{p} \leq 4\right)$ throughout except on 20 and 22 August when it increased to 6 and 7 respectively. Thus the enhancement in $f_{0} E_{s}$ data is not influenced by the magnetic storms because their effects are normally seen in the ionosphere late by few hours to few days after the date of the storm. The variations of $D_{\text {st }}$ index, shown in bottom panel, also supports this result. Hence, it may be concluded that the enhancements in $\mathrm{f}_{0} \mathrm{Es}$ between 5-15 August are due to the earthquake that occurred on 20 August 1988.

\section{Case - II : Latur earthquake of 30 September 1993}
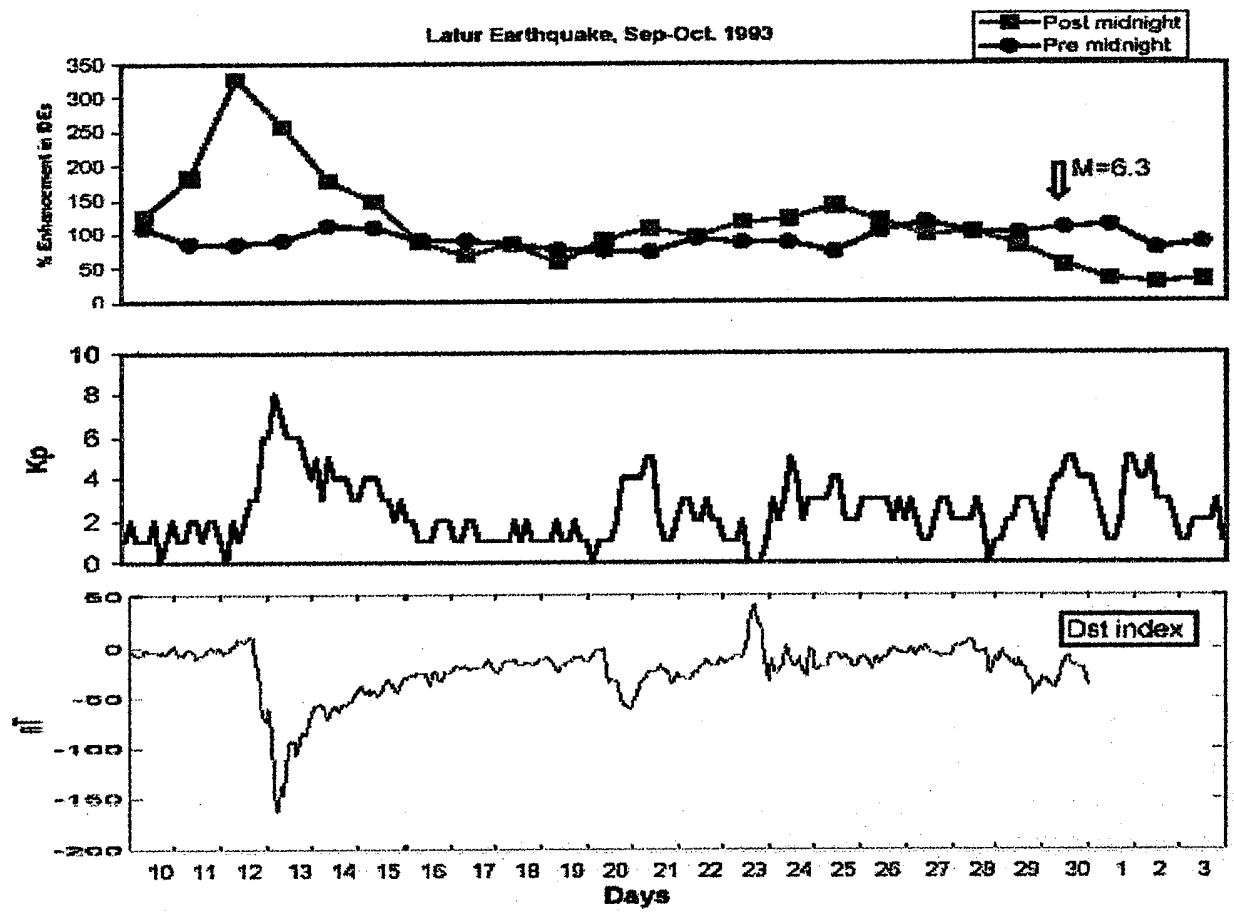

Fig. 2b. The same as Fig. 2a but for Latur earthquake $(M=6.3)$ which occurred on 30 September 1993. 
In Fig 2(b) we show the $f_{0} E_{s}$ data analysis for the month of September-October 1993 in which a severe earthquake $(M=6.3)$ occurred on 30 September 1993. The variations of pre and post midnight hours $\mathrm{f}_{0} \mathrm{E}_{\mathrm{s}}$ data along with the variations of $\mathrm{K}_{\mathrm{p}}$ and $\mathrm{D}_{\text {st }}$ indices are shown in top to bottom panels of this figure respectively. It may be seen here that a severe magnetic storm $\left(\mathrm{K}_{\mathrm{p}}=\right.$ $8, D_{\text {st }}=-161$ ) occurred on 13 September 1993, which have pronounced effect on the post midnight $f_{0} E_{s}$ which increased to $328 \%$. This large enhancement in $f_{0} E_{s}$, in fact, occurred on 15 September, two days after the magnetic storm but in the figure it appears almost simultaneous with $K_{p}$ and $D_{s t}$ because of six days running mean. The pre-midnight data is not influenced by this storm and both the pre and post midnight curves are close to each other during $15-18$ September. The post $f_{0} E_{s}$ data then increases to a maximum value of $141 \%$ on 25 September and then reduces onward. This secondary enhancement in $f_{0} E_{s}$ may not be attributed to moderate magnetic storms which occurred on 20 September $\left(K_{p}=5, D_{s t}=-61\right)$ because such storms are unlikely to influence the low latitude ionosphere. Hence, this enhancement may possibly be due to the earthquake of 30 September. The pre-midnight data show a maximum enhancement of $117 \%$ on 27 September during all the 23 days under consideration. This may also be attributed to the same earthquake and not to the moderate magnetic storms of 20 September because if there were any effect of magnetic storm on the pre-midnight data they should have appeared around 13 September because of the large magnetic storms that occurred on this date.

Case - III : Jabalpur earthquake of 22 May 1997
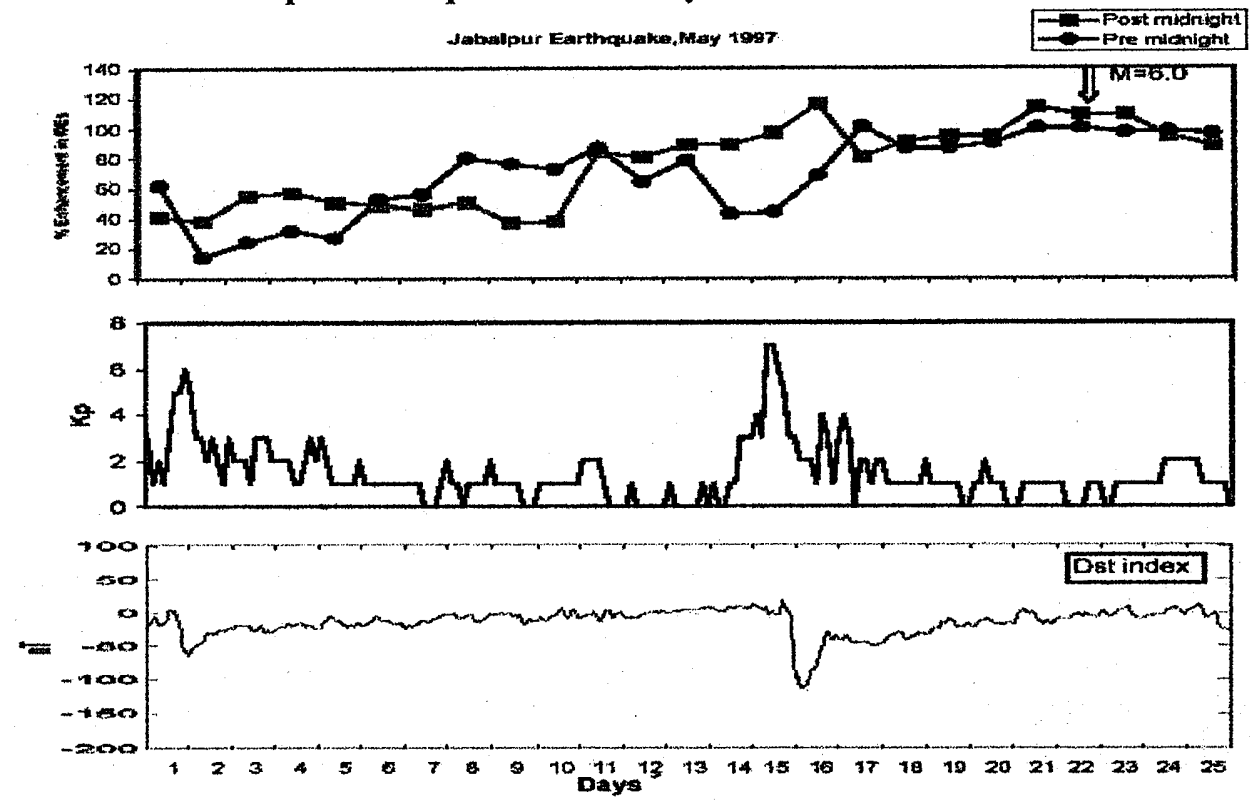

Fig. 2c. The same as Fig. 2a but for Jabalpur earthquake $(M=6.0)$ which occurred on 22May 1997. 
The $\mathrm{f}_{0} \mathrm{E}_{\mathrm{s}}$ variation on 25 days in the month of May 1997 along with $\mathrm{K}_{\mathrm{p}}$ and $\mathrm{D}_{\mathrm{st}}$ variations are shown in the three panels of Fig $2(\mathrm{c})$. In this month a severe earthquake $(M=6.0)$ occurred on 22 May at Jabalpur in Central India. As seen from the middle and bottom panels of this figure two isolated magnetic storms $\left(K_{p}=6,7\right)$ occurred on 1 and 15 May 1997. The $D_{s t}$ variation shows the values of -63 and -116 on these two days respectively. The percent enhancement in $\mathrm{f}_{0} \mathrm{E}_{\mathrm{s}}$ variation shows a gradual increase in both the pre and post-midnight data from $20-40 \%$ on 2 May to $100-114 \%$ on 21 May, 1 day before the occurrence of the earthquake. The transient increase in pre and post-midnight data between 102-116\% during 16-17 May may be attributed to the magnetic storm of 15 May. However, the gradual enhancement in both the pre and postmidnight data from nearly 20 days before may be due to the earthquake of 22 May.

From the results presented above it may be seen that the critical frequencies of the sporadic E-layers $\left(f_{0} E_{s}\right)$ are enhanced three to twenty days prior to the occurrence of the earthquakes. The precursory enhancements are distinct in the case where there is no magnetic storms prior to the occurrence of the earthquakes such as in Case-I of Bihar - Nepal Border presented in Fig 2(a). However, in the cases where there are isolated magnetic storms prior to the occurrence of earthquakes the precursory periods are not very distinct. But in the two cases related to the Latur and Jabalpur earthquakes (Fig $2 b$ and Fig $2 c$ ) the effects of magnetic storms are identified and they do not vitiate the conclusion in respect of precursory enhancements.

From the results presented in Fig 2(a)-2(c) it may be pointed that the $f_{0} E_{s}$ enhancements related to Latur and Jabalpur earthquakes are not as much convincing as that related to BiharNepal border earthquake. Though one reason for this has already been mentioned above due to occurrence of magnetic storms prior to the earthquakes, the more clear picture may appear if we look at the real data corresponding to all the three earthquakes presented in Fig 3. Here we have shown the median values by solid curve which is repeated on each day 10 days before the occurrence of the earthquakes. The actual 24 hour $\mathrm{f}_{\mathrm{o}} \mathrm{E}_{\mathrm{s}}$ data are shown by open triangles. The top panel corresponds to Bihar- Nepal earthquake whereas the middle and bottom panels correspond to Latur and Jabalpur earthquakes. The data presented in the top panel corresponding to BiharNepal earthquake supports clearly the results of Fig. 2(a). The middle panel corresponding to Latur earthquake shows enhancement in $\mathrm{f}_{0} \mathrm{E}_{\mathrm{s}}$ on two occasions, one around 22 September and the other around 27 September. The enhancement around 22 September is mostly in the mid day data which may be attributed to the magnetic storm of 22 September, although such distinct enhancements are not seen in pre and post-midnight data presented in Fig. 2(b) where we have said that moderate storm of 20 September may not influence the $f_{0} E_{s}$. The enhancement around 27 September which is the same as that on 25 September in Fig.2(b) due to running averages may be attributed very well to the earthquake occurring on 30 September. The data in the bottom panel corresponding to Jabalpur earthquake show clearly the large enhancement on 19 May, three days before the occurrence of the earthquake. 


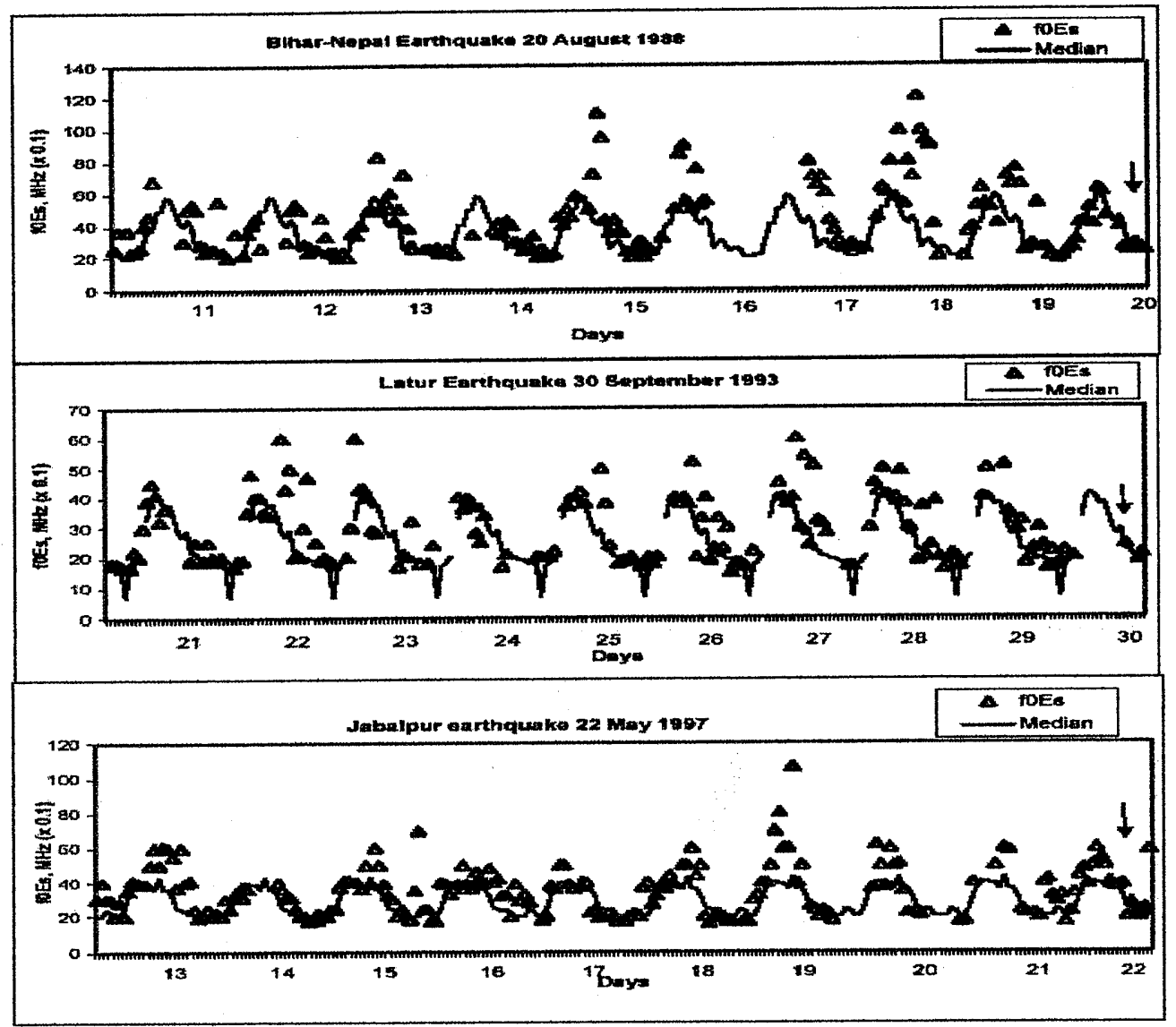

Fig. 3. Monthly median of $f_{o} E_{s}$ (solid curves) and hourly measured values (open triangles) for ten days before the occurrence of earthquakes in the months of August, 1998 (top ), September, 1993 (middle) and May 1997 (bottom). The inverted arrows indicate the days of the earthquakes. Magnitude of the earthquakes are already given in Fig. 2.

A small enhancement on 15 May is due to the magnetic storm that occurred on this day. Hence the variation of actual $f_{o} E_{s}$ in all the three cases presented in Fig.3 confirms precursory enhancements in the data.

Our results presented above may be questioned on the ground that since the ionospheric station is located far away $(1100-2500 \mathrm{Km})$ from epicenters of the earthquakes how the ionospheric E-layer will be perturbed by these earthquakes . Further, the precursory period of enhancements in the case of Latur earthquake, which occurred at a depth of $12 \mathrm{Km}$ and location $1100 \mathrm{Km}$ from the ionospheric station, is less than those in the rest of the two earthquakes which occurred at relatively larger depths and far away from the ionospheric station. In order to answer the first question we may refer here the ground and satellite based results of Pulinets et al. (1994) 
in which it has been reported that the effect of the earthquakes is wide spread, $30^{\circ}$ in latitude and $60^{\circ}$ in longitude. In the light of this it is possible that the earthquakes considered here may have influenced the ionospheric E-layer over Ahmedabad. The answer of the second question is difficult to be given at the moment because it depends upon the crust characteristics, fault locations, type of rapture, etc. which have not been studied by us in relation to the work presented here.

The results of $f_{0} E_{s}$ enhancements prior to the occurrence of the earthquakes have been reported by several workers in the past and possible mechanisms involved in lithosphereionosphere coupling have been suggested . For example, Pulinets et al. (1994) have observed similar $\mathrm{f}_{0} \mathrm{E}_{\mathrm{s}}$ anomalies prior to the occurrence of the earthquakes and explained the results in terms of diffusion of metallic ions in the E-region ionosphere which are emanated from earthquake sources and driven by earthquake generated electric fields. However, this explanation has been questioned on the ground that metallic ions would take much longer time ( $\sim 15$ days) to diffuse in the E-region ionosphere (O.A. Molchanov, Personal Communication, International Workshop on Seismo-electromagnetics, Chofu, Tokyo, 2002). The $\mathrm{f}_{0} \mathrm{E}_{\mathrm{s}}$ enhancements prior to the occurrence of large earthquakes have also been reported by Ondoh and Hayakawa (2002), and Ondoh (2003), but they have suggested such enhancements due to radon emanations from seismic sources which are carried upward by the electric field substantially increased before the earthquakes and penetrated into the heights of E-layer. Radon emanations 100 times larger than the normal density have been found at epicenter distance of about $200 \mathrm{Km}$ before the Kobe earthquake. Such large emanations of radon alongwith other gases like helium, carbon dioxide, hydrogen, and mercury with duration of few hours to few days have also been reported by King (1986) from observation along active faults at epicentral distances within about $500 \mathrm{~km}$ before great earthquakes.

The $f_{0} E_{s}$ enhancements prior to the occurrence of the earthquakes have also been interpreted in terms of lithosphere ionosphere coupling given by earthquake induced electric fields. It has been suggested that if the epicenter of the earthquakes are located in the equatorial and low latitude regions the generated electric fields can penetrate to the E layer heights and intensify the electrojet strength. The upward ExB drift will then be amplified thereby augmenting the density pumping process from the epicentral zone to off epicenter positions in the ionosphere (Ruzhin and Depueva, 1996). The other possibility is quasi statistic heating and production of additional ionization in the sporadic $E$ layers caused by cloud discharge in the atmosphere over seismic zones induced by seismic electric fields (Ondoh and Hayakawa, 2002; Ondoh, 2003).

Acknowledgements. The authors are thankful to the Department of Science \& Technology, New Delhi for financial support in the form of major research project. Thanks are also due to our research colleagues Mr. Manoj Tomar, Mr. Vinod Kushwah, and Mr. Vikram Singh for help in analysis of data and preparation of figures. One of the authors (BS) is thankful to CSIR, New Delhi for support under Emeritus Scientist scheme. We are also thankful to Ishikawa Fund in Japan for partial support in respect of publication of the paper. 


\section{References}

Appleton, E.V. and Ingram, L.J., Magnetic storms and upper atmospheric ionization, Nature, Lond., 136, 548-549, 1935.

Behnke, R.A., Vector measurements of the ion transport velocity with application to F-region dynamics, Ph.D. thesis, Rice Univ., Houseton, Tex., 1970.

Berkner, L.V., Wells, H.W. and Seaton, S.L., Ionospheric effects associated with magnetic disturbances, Terr. Magn. Atmos. Elect. 44, 283-311, 1939.

Carpenter, D.L., Relations between the dawn minimum in the equatorial radius of the plasma pause and $\mathrm{D}_{\mathrm{st}}, \mathrm{K}_{\mathrm{p}}$ and local $\mathrm{K}$ at Byrd Station, J. Geophys. Res. 72, 2969-2971, 1967.

Chappel, C.R., Harris, K.K. and Sharp, G.W., The morphology of the bulge region of the plasma sphere, J. Geophys. Res., 75, 3848-3861, 1970.

Chuo, Y.J., Liu, J.Y., Pulinets, S.A. and Chen, Y.I., The ionospheric perturbations prior to the Chi-Chi and Chia Yi earthquakes, J. Geodynamics, 33, 509. $517,2002$.

Davies, K. and Baker, D.M., Ionospheric effects observed around the time of the Alaskan earthquake of March 28, 1964, J. Geophys. Res., 70, 2251-2263, 1965.

Datchenko, E.A., Ulomov, V.I. and Chernyshova, S.G., Anomalies of ionosphere electron density as a possible precursor of the Tashkent earthquake, Doki Akad Nauk Uzbek, SSR, 30-31, 1972.

Fatkullin, M.N., Zelenova, T.I. and Legen'ka, A.D., On the ionospheric effects of asthenospheric earthquakes, Phys. Earth Planet. Inter., 57, 82, 1989.

Gokhberg, M.B., Kolocolov, L.E., Liperovski, V.A., Pokhotelov, O.A., Buloshnikov, A.M., Marakhovski, A.V. and Liperovskaya, E.V., Manifestation of the strong earthquakes preparing effects in the sporadic $E_{\mathrm{s}}$ layers on different latitudes, Preprint IFZRAN. No.1, 1988.

Hayakawa, M., Molchanov, O.A., Ondoh, T. and Kawai, E., The precursory signature effect of the Kobe earthquake in VLF subionospheric signal, J. Comm. Res. Lab., Tokyo, 43, 169-180, 1996a.

Hayakawa, M., Molchanov, O.A., Ondoh, T. and Kawai, E., Anomalies in the subionospheric VLF signals for the 1995 Hyogoken Nanbu earthquake, J. Phys.Earth, 44, 413-418, 1996 b.

Hayakawa, M., Atmospheric and ionospheric electromagnetic phenomena associated with earthquake, Terra Sci. Pub. Co. Tokyo, 1999.

Hayakawa, M. and Fujinawa, Y., Electromagnetic phenomena related to earthquake prediction, Terra Sci. Pub. Co. Tokyo, 1994.

Hayakawa, M. and Molchanov, O.A., Lithosphere-atmosphere-ionosphere coupling, Terra Sci. Pub. Co. Tokyo, 2002.

Jain, S.K. and Singh, B., Vertical motion of low and equatorial latitude $f_{0} F_{2}$ during 
prolonged and isolated magnetic storms, J. Geophys. Res., 82, 773, 1977. King, C.Y., Gas geochemistry applied to earthquake prediction: an overview, J. Geophys. Res., 91, B12, 12281, 1986.

Lakshmi, D.R., Reddy, B.M. and Sastri, S., A prediction model for equatorial low Latitude HF communication parameters during magnetic disturbances, Indian J. Radio \& Space Phys., 12, 1-18, 1983.

Liperovski, V.A., Pokhotelov, O.A. and Shalimov, S.L., Ionospheric precursors of the earthquakes, Nauka Publ., Moscow, 1992.

Liu, J.Y., Chen, Y.I., Pulinets, S.A., Tsai, Y.B. and Chuo, Y.J., Seismo ionospheric signature prior to $M \geq 6.0$ Taiwan earthquakes, J. Geophys. Res., 27, 3113-3116, 2000.

Liu, J.Y., Chen, Y.I., Chuo, Y.J. and Tsai, H.F., Variations of ionospheric total electron content during the Chi-Chi earthquake, J. Geophys. Res., 28, 1383-1386, 2001.

Matsushita, S.C., A study of the morphology of the ionospheric storms, J. Geophys. Res., 64, 305-321, 1959.

Molchanov, O.A. and Hayakawa, M., Subionospheric VLF signal perturbations possibly related to earthquakes, J. Geophys. Res., 103 (A 8), 17489$17504,1998$.

Obayashi, T., On the world-wide disturbance of the ionosphere, Rep. Ionosph. Space. Res. Japan, 8, 135-142, 1954.

Ogawa, T., Takahashi, O., Otsuka, Y., Nozaki, K., Yamamoto, M. and Kita, K., Simultaneous middle and upper atmosphere radar and ionospheric sounder observations of mid latitude E-region irregularities and sporadic $E$ layers, J. Geophys. Res., 107 ( A 10 ), doi: 10.1029/2001 JA 900176, 2002.

Ondoh, T., Seismo ionospheric phenomena, Adv. Space. Res., 26, 8, 1267-1272, 2000.

Ondoh, T., Anomalous sporadic E-layers observed before M 7.2 Hyogo-ken Nanbu earthquake; Terrestrial gas emanation model, Advances in Polar Upper Atmosphere Research, No.17, 96-108, 2003.

Ondoh, T. and Hayakawa, M., Anomalous occurrence of sporadic E-layers before the Hyogoken-nanbu earthquake, M 7.2 of January 17, 1995, Atmospheric and Ionospheric Electromagnetic Phenomena Associated with Earthquakes, Ed. M. Hayawaka, Terra Sci. Pub. Co.Ltd., Tokyo, 629-639, 1999.

Ondoh, T. and Hayakawa, M., Seismo discharge model of anomalous sporadic E ionization before great earthquakes, Seismo Electromagnetic :

Lithosphere-Atmosphere Coupling, Eds. M. Hayakawa and O.A. Molchanov, Terra Sci. Pub. Co.Ltd., Tokyo, 385-390, 2002.

Pulinets, S.A., Legen'ka, A.D., Karpachev, A.T., Kochenova, N.A., Migulin, V.V., Orveski, V.N. and Fligel, M.D., On the possibility of earthquakes prediction on the basis of topside satellite sounding, Preprint IZIMIRAN, No.34a (981), 1991. 
Pulinets, S.A., Legen'ka, A.D. and Aleskeev, V.A., Pre earthquake ionospheric effects and their possible mechanisms, Dusty and dirty plasmas, noise, and chaos in space and in the laboratory, Ed. H. Kikuchi, Plenumn Press, New York, 545-557, 1994.

Reutov, A. P. and Morenko, V.F., Concept of radio wave forecasting system and experimental results, Moskow, IIA, 46, 1995.

Ruzhin, Yu.Ya. and Depueva, A.Kh., Seismo precursor in space plasma and wave anomalies, J. Atmos. Electr., 16, 271-288,1996.

Singh, B., Kushwah, V., Singh, O.P., Lakshmi, D.R. and Reddy, B.M., Ionospheric perturbations caused by some major earthquakes in India, J. Phys. Chem. Earth (Special Issue ) 29, 537-550, 2004.

Taylor, H.A., Brinton, H.C. and Pharo (III), M.W., Contraction of the plasma sphere during geomagnetically disturbed periods, J. Geophys. Res., 73, 961-968, 1968.

Warren, E.S., The topside ionosphere during geomagnetic storms, Proc. IEEE 57, 1029-1036, 1969.

Wright, J.W., Horizontal drifts accompanying large vertical motions of the nocturnal F-region, Planet. Space Sci., 19, 1327, 1971.

(Received June 22, 2004; revised September 30, 2004; accepted October 5, 2004) 